\title{
Effects of emulsifying components in the continuous phase of cream on the stability of fat globules and the physical properties of whipped cream
}

\author{
K. Ihara, ${ }^{* 1}$ M. Hirota, ${ }^{*}$ T. Akitsu, $\dagger$ K. Urakawa, ${ }^{*}$ T. Abe, ${ }^{*}$ M. Sumi, $\dagger$ T. Okawa, ${ }^{*}$ and T. Fujiił \\ *Food Research and Development Institute, and \\ †Product Evaluation Center, Morinaga Milk Industry Co., Ltd., 1-83, 5-Chome Higashihara, Zama, Kanagawa 252-8583, Japan, and \\ $\ddagger$ Graduate School of Agricultural Science Faculty of Agriculture, Tohoku University, 1-1, Amamiya-machi, Tsutsumidori, Aoba-ku, Sendai, \\ Miyagi 981-8555, Japan
}

\begin{abstract}
The emulsifying components in cream are very important in controlling the physical characteristics of whipped cream. The effects of those components on the stability of fat globules and the physical characteristics of whipped cream were investigated. A low-molecularweight emulsifier, and protein ingredients such as sodium caseinate and a casein partial hydrolysate (casein peptides), were used as emulsifying components in this investigation. The viscosity of deaerated whipped cream (called the serum viscosity) was measured to evaluate the degree of fat-globule aggregation. Furthermore, the shape-retention ability, which is the degree of reduction in the firmness of whipped cream between immediately after whipping and after $1 \mathrm{~d}$ of refrigeration, was explored. The addition of the low-molecular-weight emulsifier in the continuous phase of dairy cream, which does not contain added low-molecular-weight emulsifiers, increased the stability of the fat globules and reduced the shape-retention ability of the whipped cream. The addition of protein ingredients (sodium caseinate and casein peptides) to the continuous phase of dairy cream had little effect. However, the addition of casein peptide in the continuous phase of dairy cream together with the low-molecular-weight emulsifier reduced the effect of the low-molecular-weight emulsifier on the stabilization of fat globules and the shape-retention ability of the whipped cream. The addition of casein peptide did not recover the serum viscosity; thus, other mechanisms might underlie this phenomenon.
\end{abstract}

Key words: cream, emulsification, physicochemical properties, whipping

\section{INTRODUCTION}

The whipping of cream introduces air and initiates the aggregation of fat globules; ultimately, the cream

Received September 17, 2014.

Accepted January 9, 2015.

${ }^{1}$ Corresponding author: k_ihara@morinagamilk.co.jp gains firmness and is transformed into a whipped cream (Van Aken, 2001; Hotrum et al., 2005; Ihara et al., 2010). However, the physical characteristics of whipped creams are unstable, which may cause adverse effects on the flavor release, mouth feel, and appearance. Hotrum et al. (2005) reported that a whipping process can be divided into 3 phases: (1) air is incorporated into the cream and the proteins adsorb onto the surface of the air bubbles, (2) the fat globules adsorb onto the surface of the bubbles/proteins, and (3) a network of the fat globules is formed in the whipped cream. Therefore, demulsification of fat globules is necessary to enable the formation of a network of fat globules. Controlling the fat crystal forms is one of the methods used to control the demulsification of fat globules (Fredrick et al., 2010). The control of the fat crystal forms can be achieved using several types of oil or oil-soluble lowmolecular-weight emulsifiers (LMWE; Fredrick et al., 2013; Zhao et al., 2013). Low-molecular-weight emulsifiers are reported to cause proteins to desorb from the surface of fat globules (Wilde and Clark, 1993; Cornec et al., 1998; Fredrick et al., 2013), diminish the shear stability (Cornec et al., 1998), and stimulate the aggregation of fat globules during the whipping process (Hotrum et al., 2005). Moreover, the stability of fat globules increases with the concentration of proteins in the continuous phase of a cream (Goff, 1997; Fredrick et al., 2010). The oil and fat-globule membrane conditions thus control the stability of fat globules.

Dairy cream and recombined creams are known as whipping creams. Dairy cream, which is derived from raw milk, does not contain additives such as additional proteins or LMWE. This makes it difficult to control the physical characteristics of dairy cream, such as its stability against shear (shear stability) and its whipping properties. On the other hand, recombined creams are produced by mixing and emulsifying an oil phase and a water phase, which has several components. Various oils and emulsifying components can be used in recombined creams, which makes it easier to actively control the shear stability and whipping properties of recombined creams compared with dairy cream. 
Whipping creams should be stable against vibration during storage and should be properly partially coalesced at the time of whipping. These characteristics that conflict with each other, and hence several emulsifiers are often used to support these characteristics in whipping cream products. Emulsifiers can confer emulsifying or demulsifying characteristics on the fat globules of cream (Fredrick et al., 2013; Zhao et al., 2013). Proteins also adsorb onto the membrane of fat globules, forming a steric barrier and strengthening the membrane (Matsumura and Matsumiya, 2012). Emulsions acquire stability through the adsorption of proteins onto the surface of fat globules (Wilde et al., 2007). It has also been reported that the addition of LMWE that contain unsaturated fatty acids reduce the density of the fat globule membrane, thus weakening it (Fredrick et al., 2013). Therefore, the stability of the fat globules against shear stress using this type of emulsifier is low, thus stimulating demulsification during the whipping process (Fredrick et al., 2013). The influence of emulsifying components on the stability of fat globules in turn controls the whipping properties. These emulsifying components also exist in a continuous phase and are thought to greatly influence the shear stability and whipping properties, although little research has been conducted to clarify this.

The present study compared the characteristics of recombined cream and dairy cream, and determined the total influence of the emulsifying components on the stability of fat globules and whipping properties of the 2 products. Furthermore, the effect of adding emulsifying components in the continuous phase of cream was analyzed.

\section{MATERIALS AND METHODS}

\section{Creams}

Shear stability, which is the effect of shear stress on fat globules, was evaluated in both a $45 \%$ (wt/wt) fat dairy cream and a $45 \%$ (wt/wt) fat recombined cream containing $0.3 \%$ (wt/wt) LMWE and $1.6 \%$ (wt/ wt) protein (Morinaga Milk Industry, Tokyo, Japan). For the LMWE tests, a $47 \%$ (wt/wt) fat dairy cream (Morinaga Milk Industry) was mixed with skim milk containing a LMWE and its fat content was adjusted to $45 \%$ (wt/wt).

\section{Protein Ingredients and LMWE}

Sodium caseinate (Tatua, Morrinsville, New Zealand) and casein partial hydrolysate (referred to as casein peptide) with a hydrolysis level of $8 \%$ (Morinaga Milk
Industry) were used as protein ingredients. Polyglyceryl monostearic acid ester (Sakamoto Yakuhin Kogyo, Osaka, Japan) was used as LMWE in this study.

\section{Shear Stability}

The shear stability of whipped cream was evaluated using a cone-plate viscometer (Physica MCR301, Anton Paar, Ashland, VA). Measurements were carried out at $15^{\circ} \mathrm{C}$ with a shear rate sweep from 0 to $1,800 \mathrm{~s}^{-1}$ in $3 \mathrm{~min}$. The viscosity of whipping creams increases under shear stress (Okuyama et al., 1995) as a result of fat-globule aggregation (Walstra et al., 2006), and hence this measurement can be used to quantify the shear stability of cream.

\section{Microscopic Observation}

In the shear stability test, cream was collected when the shear rate reached a prescribed value, and its fat globules were observed using a scanning electron microscope equipped with a cryostage.

\section{Whipping Conditions}

A batch mixer (Kenwood Mixer Major, Kenwood, Watford, UK) was used to beat $1 \mathrm{~kg}$ of cream to which $80 \mathrm{~g}$ of sugar had been added, at an initial temperature of $7^{\circ} \mathrm{C}$, to produce whipped cream. The end point of whipping was defined as when the cone penetration depth (PD), which is described in the next section, reached $20.0 \pm 1.0 \mathrm{~mm}$. At this end point, the whipped cream exhibited what is considered a good texture for decorating a cake.

\section{Firmness of Whipped Creams}

A cone-penetration test and dynamic viscoelasticity measurement were conducted to evaluate the firmness of whipped creams using the method described by Ihara et al. (2010). The cone-penetration test was carried out to determine the end point of whipping. This method can rapidly determine the firmness of a whipped cream. Dynamic viscoelasticity was used as a measure of shape-retention ability, as described below.

A cone penetrometer equipped with a cone (front edge angle, $40^{\circ}$; weight, $12 \mathrm{~g}$; upper diameter, $24 \mathrm{~mm}$; length, $33 \mathrm{~mm}$ ) was used in the cone-penetration test, and the PD was defined as the cone PD at $5 \mathrm{~s}$ after dropping it under its own weight from the whippedcream surface. In the dynamic viscoelasticity measurement, the storage modulus $\left(\mathbf{G}^{\prime}\right)$ of the whipped creams was measured using a dynamic viscoelasticity measur- 
ing instrument (Rheometric Dynamic Analyzer ARES, TA Instruments, New Castle, DE) under the following conditions: sample thickness, $2 \mathrm{~mm}$; temperature, $5^{\circ} \mathrm{C}$; strain, $0.1 \%$; and frequency, $1 \mathrm{~Hz}$. The result was taken as the average of 3 measurements.

\section{Serum Viscosity}

Serum viscosity is the viscosity of a deaerated whipped cream (Noda and Shiinoki, 1986). Deaerated whipped cream consists of fat-globule agglomerate and skim milk. The difference between unwhipped cream viscosity and serum viscosity is the existence or nonexistence of fat-globule agglomerate; thus, serum viscosity can be used to evaluate the state of fat aggregation. This value of serum viscosity increases with the progress of the whipping process and influences the firmness of the whipped cream (Ihara et al., 2010).

Serum viscosity was measured using a method based on that described by Noda and Shiinoki (1986). A 3-g sample of whipped cream was deaerated using a vacuum pump at $10 \mathrm{~Pa}$ and a serum sample was prepared. The viscosity was measured by a cone-plate rotational viscometer (RotoVisco 1, Thermo Electron, Karlsruhe, Germany) at a shear rate of $300 \mathrm{~s}^{-1}$. The result was taken as the average of 3 measurements.

\section{Shape-Retention Ability of Whipped Cream}

Shape-retention ability can be described as the difference in the firmness of whipped cream measured immediately after whipping and after $1 \mathrm{~d}$ of refrigeration. In this research, the initial firmness of the whipped creams was set to the same level; therefore, the value of $\mathrm{G}^{\prime}$ after $1 \mathrm{~d}$ of refrigeration itself was taken to represent the shape-retention ability.

\section{RESULTS AND DISCUSSION}

\section{Evaluation of the Shear Stability of Dairy Cream and Recombined Cream}

Dairy cream, which is often used as whipping cream, is produced by separating the cream and skim milk from raw milk; it does not contain any additives such as LMWE. Recombined creams are produced by emulsifying an oil phase and a water phase; they do contain LMWE and protein that impart good whipping properties. In theory, the differences between a dairy cream and a recombined cream should provide information regarding the characteristics of the emulsifying components in the recombined cream. Demulsification of fat globules is one of most the important factors underly- ing the firmness of whipped cream (Ihara et al., 2005, 2010). Thus, the effects of the emulsifying components on the stability of fat globules were evaluated by measuring their shear stabilities and changes in fat-globule shape.

The shear stability of the dairy cream is shown in Figure 1a. The viscosity doubled at shear rates between 200 and $400 \mathrm{~s}^{-1}$, plateauing at $1,000 \mathrm{~s}^{-1}$, after which it increased rapidly, reaching a maximum at about 1,200 $\mathrm{s}^{-1}$, and then decreased because the agglomerate of fat globules was ejected from the cone plate. The shear stability of the recombined cream, which is shown in Figure 1b, peaked twice, first at around $400 \mathrm{~s}^{-1}$, reducing slightly thereafter to a local minimum viscosity at around $750 \mathrm{~s}^{-1}$, and then increasing to a second peak of viscosity at around $1,300 \mathrm{~s}^{-1}$. The shape of the fat glob-

(a)

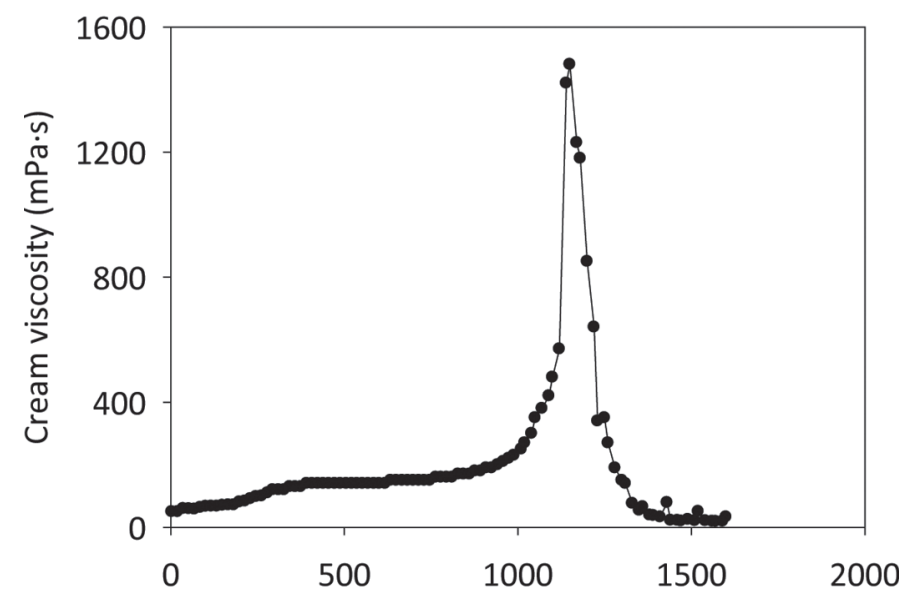

(b)

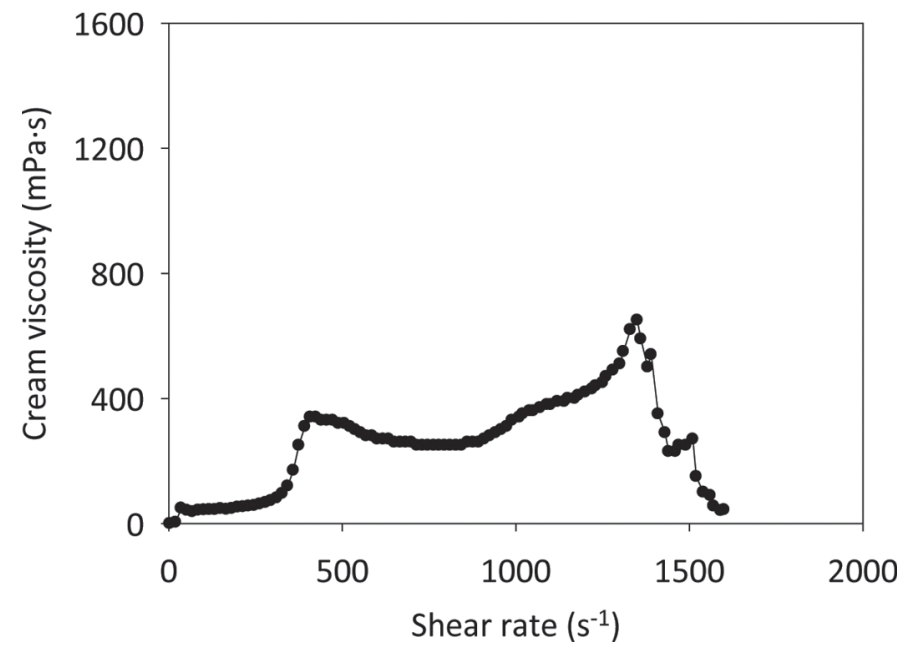

Figure 1. Changes in viscosities of dairy cream (a) and recombined cream (b) in the shear-stability test. 
(a)

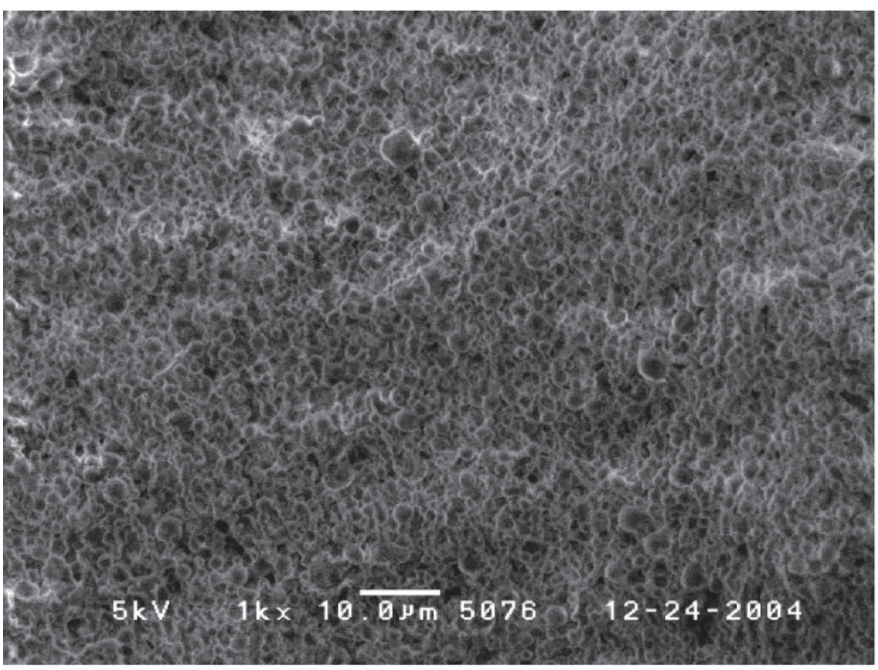

(c)

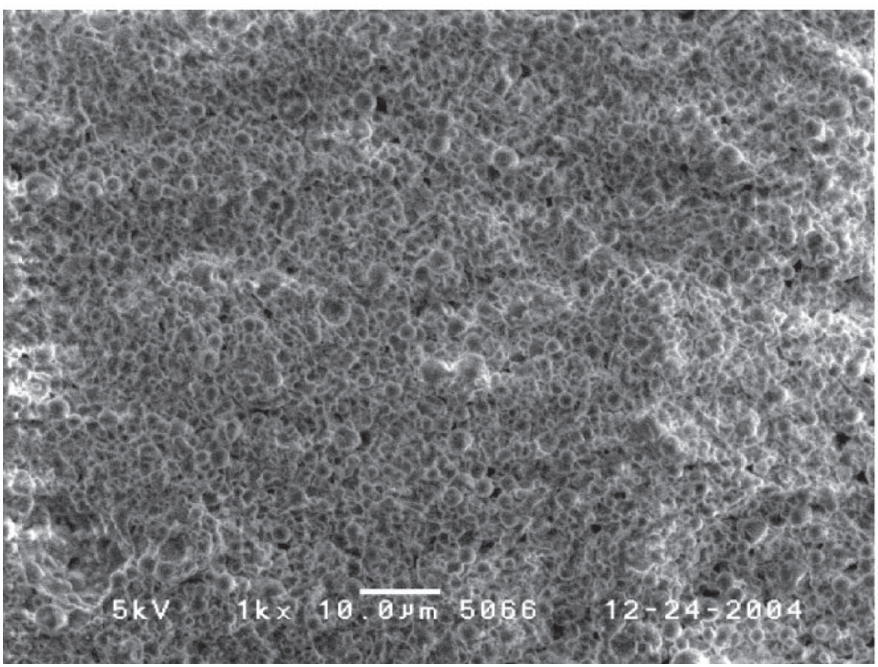

(b)

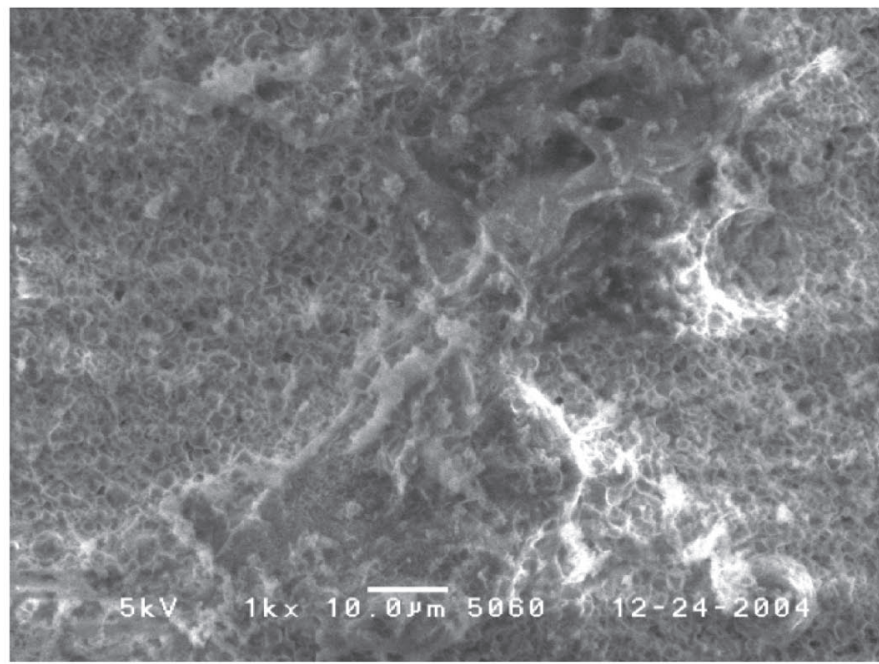

(d)

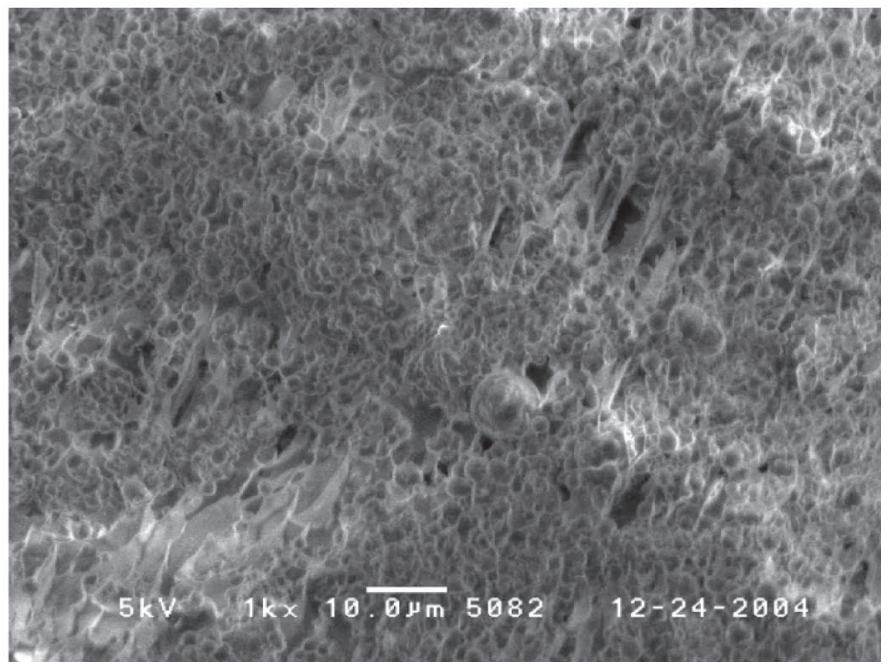

Figure 2. Results of the shear-stability test. Scanning electron microscope observations of fat globules of the recombined cream (a) before the test, (b) at the first peak $\left(400 \mathrm{~s}^{-1}\right)$, (c) in the region of the local minimum $\left(750 \mathrm{~s}^{-1}\right)$, and (d) immediately before the second peak $\left(1,300 \mathrm{~s}^{-1}\right)$.

ules at each shear rate was observed using an scanning electron microscope (Figure 2). Substances that looked like free fat were found at the first peak; these substances disappeared at the local minimum viscosity and reappeared immediately before the second peak. Walstra et al. (2006) reported that a small amount of liquid oil seeping out from fat globules acts as an adhesive agent in the whipping process; this liquid oil adhesion was thus thought to be responsible for the first peak in the viscosity of the cream. If oil is separated from water phase, the viscosity of cream decreases. On the other hand, if damaged fat globules are re-emulsified and the agglomerate of fat globules is dissolved, the viscosity of cream also decreases. Oil separation was not observed in the region of the local minimum; thus, the reduction in viscosity was thought to be caused by stabilization of the emulsion. In other words, partially coalesced fat globules may have been re-emulsified during the whipping process by LMWE in the continuous phase of the recombined cream at high shear rates.

\section{Influences of LMWE in the Continuous Phase of Dairy Cream on the Physical Properties}

The aforementioned hypothesis that LMWE in the continuous phase of creams re-emulsify the damaged 


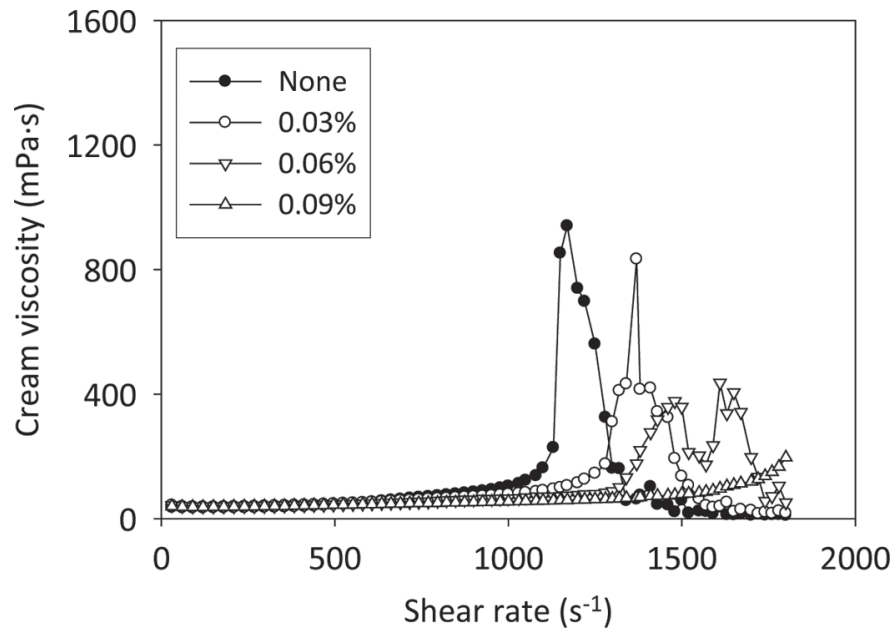

Figure 3. Change in viscosity of the dairy cream with the emulsifier added at 0.00 (none), $0.03,0.06$, and $0.09 \%$ in the continuous phase in the shear-stability test. The concentration values refer to the percentage of total cream.

fat globules under the condition of a high shear speed was tested by adding LMWE to the continuous phase of a dairy cream. It was predicted that upon the addition of LMWE, the dairy cream would become more stable than the original cream, and that the degree of fat agglomeration in the whipped cream would decrease, resulting in a reduction in the shape-retention ability. The results of the shear-stability tests are shown in Figure 3. The shear stability was found to stabilize, and the serum viscosity and shape-retention ability were reduced with increasing concentrations of LMWE in the continuous phase (Figure 4). These findings indicate that the emulsifier in the continuous phase has an effect on the stability of fat globules, which is consistent with the hypothesis.

\section{Influences of Protein Components Added to the Continuous Phase of Dairy Cream on the Physical Properties}

It is thought that the LMWE in the continuous phase stabilize the fat globules in dairy cream. Thus, other emulsifying components were investigated. Protein ingredients such as skim milk powder and sodium caseinate are also used as food-emulsifying components. In this study, casein, which is a dairy protein, and its hydrolysate (casein peptide) were used, both of which have a strong emulsifying ability (Britten and Giroux, 1991; Panyam and Kilara, 2004). Sodium caseinate and casein peptide, which were dissolved in skim milk, were added to the continuous phase of a dairy cream, to a concentration of 0 to $0.66 \%$ (wt/wt) of total cream. (a)

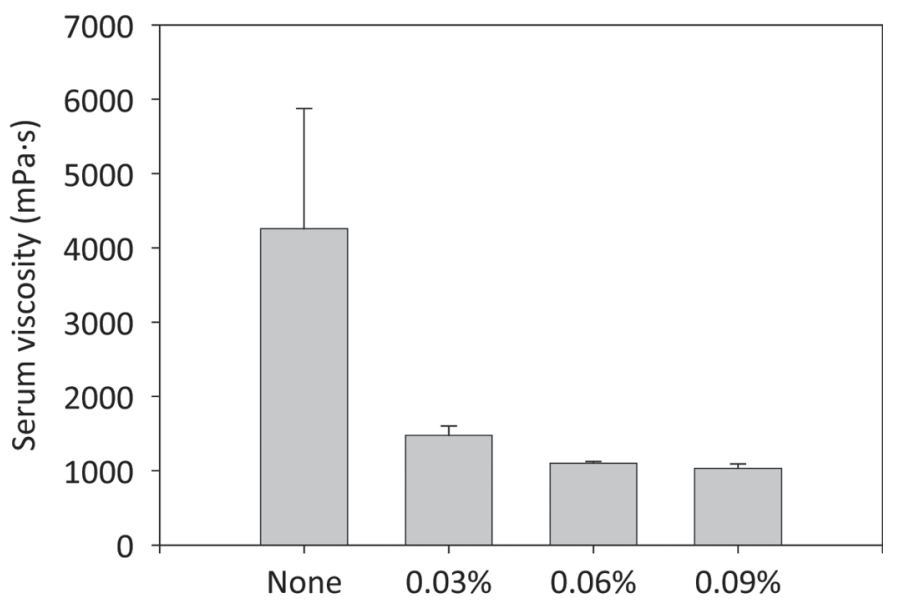

(b)

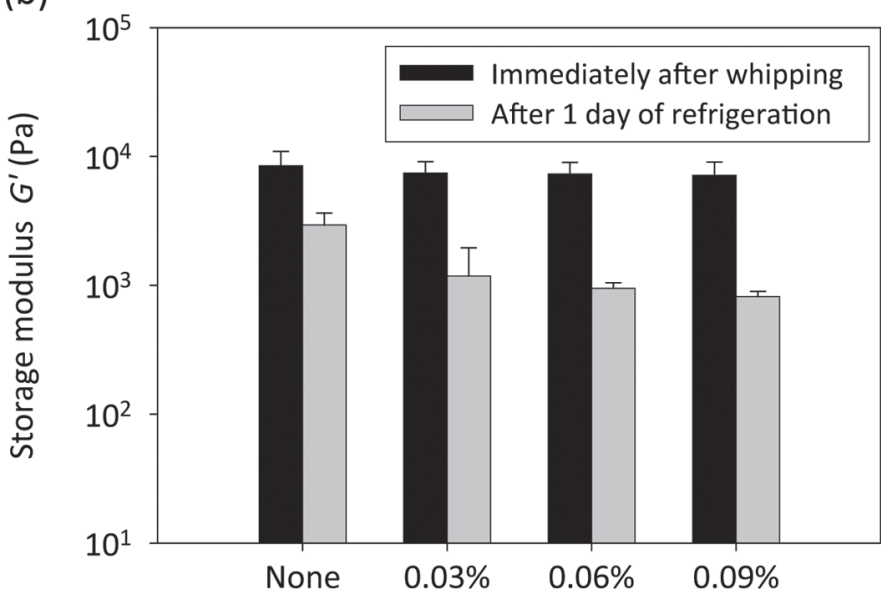

Figure 4. (a) Serum viscosity and (b) shape-retention ability (as defined by the storage modulus, $\mathrm{G}^{\prime}$ ) of the cream with the emulsifier added in the continuous phase. The $\mathrm{x}$-axis indicates the concentration of the added emulsifier as a percentage of the cream. Data are mean and standard deviation values $(\mathrm{n}=3)$.

However, sodium caseinate could not be added at a concentration of $0.66 \%$ (wt/wt) because of the high viscosity of its skim milk solution. The addition of those components did not greatly influence either the shear stability or the serum viscosity (Figures 5 and 6). However, the shape-retention ability of cream to which sodium caseinate was added to a concentration of $0.33 \%$ (wt/wt) was reduced, whereas that of cream to which casein peptide was added increased up to a concentration of $0.5 \%$ (wt/wt; Figure 7 ). Changes in the shear stability and serum viscosity were not obvious (Figures 5 and 6); thus, mechanisms other than fat-globule aggregation (which is often used to explain shape-retention ability) may be responsible for this change in the shape-retention ability. 
(a)

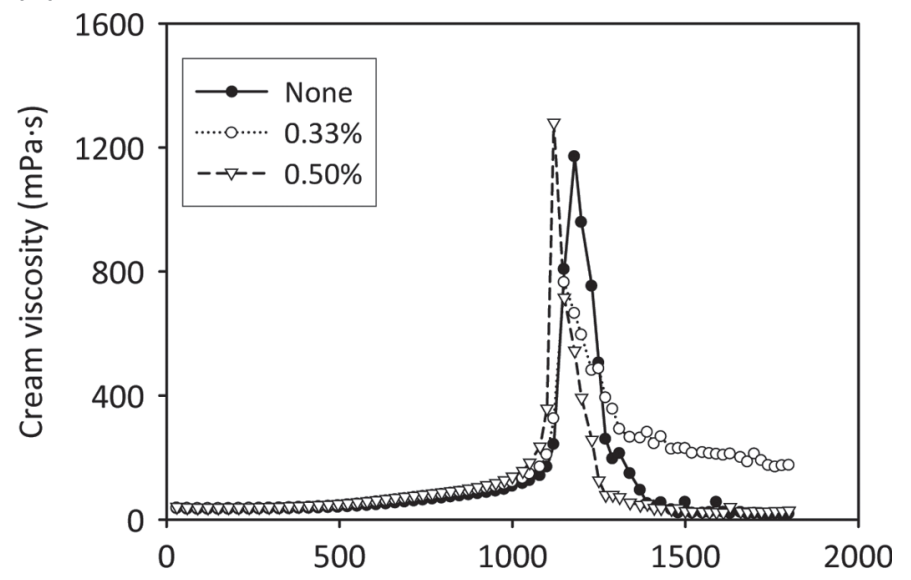

(b)

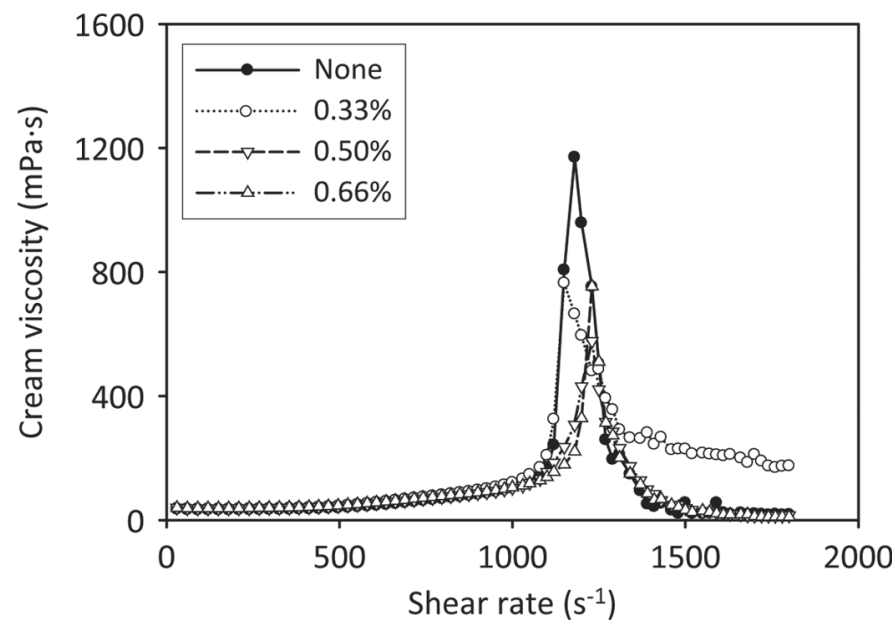

Figure 5. Shear stability of the dairy cream with (a) sodium caseinate and (b) casein peptide in the continuous phase. The concentration values refer to percentages of sodium caseinate or casein peptide relative to cream.

Proteins adsorb onto air bubbles in the early stage of the whipping process (Hotrum et al., 2005); thus, the air bubbles in the cream might be one of the factors responsible for the change in the shape-retention ability. In addition, the shape-retention ability of cream with casein peptide was high up to a concentration of $0.5 \%$ (wt/wt; Figure 7). Therefore, it appears that some peptides in this casein peptide may confer shape-retention ability.

We found that LMWE increase the stability of fat globules; thus, the effect of coexistence of a LMWE and an additional protein component in the continuous phase on the stability of fat globules and on shaperetention ability was investigated. The concentrations of the emulsifier and the protein component (sodium caseinate or casein peptide) were $0.06 \%$ (wt/wt) and

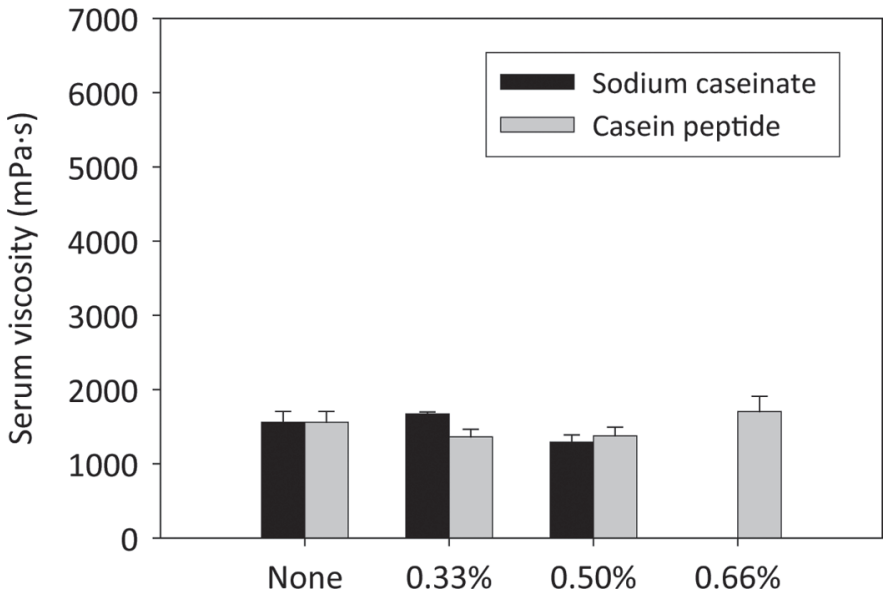

Figure 6. Serum viscosity of the cream with sodium caseinate or casein peptide in the continuous phase. The $\mathrm{x}$-axis indicates the concentration of each protein component relative to that of the total cream. Data are mean and standard deviation values $(\mathrm{n}=3)$.

0 to $0.66 \%$ (wt/wt), respectively, although it should be noted that data for sodium caseinate at $0.66 \%$ (wt/ wt) could not be obtained because of the high viscosity of its skim milk solution. The major difference in the shear stability between cream with emulsifier with sodium caseinate and with casein peptide was that no difference was observed with increasing concentration of the former (Figure 8a), whereas that measured with the latter increased with the concentration (Figure 8b). However, the serum viscosity of the whipped cream varied little with increasing concentrations of casein peptide (Figure 9). The whipping process was considered complete at the point at which the whipped cream reached the same level of the firmness; thus, the serum viscosity might be independent of the change in the shear stability. In addition, the shape-retention ability of the whipped cream with sodium caseinate was relatively low at the concentration of $0.33 \%$ (wt/wt); that of the whipped cream with casein peptide increased up to a concentration of $0.5 \%$ (wt/wt; Figure 10). This finding is similar to that of the protein-simple-addition test, although the level of the shape-retention ability was different.

The addition of the LMWE stabilized the fat globules, resulting in a reduction in serum viscosity and a consequent reduction in the shape-retention ability with increasing concentrations. This effect was reversed to some degree by the addition of casein peptide to the continuous phase. The stability of the fat globules increased and the serum viscosity, which is often thought to influence the shape-retention ability of whipped cream, was maintained at the same level. Therefore, it appears that other mechanism(s) may influence the 
(a)

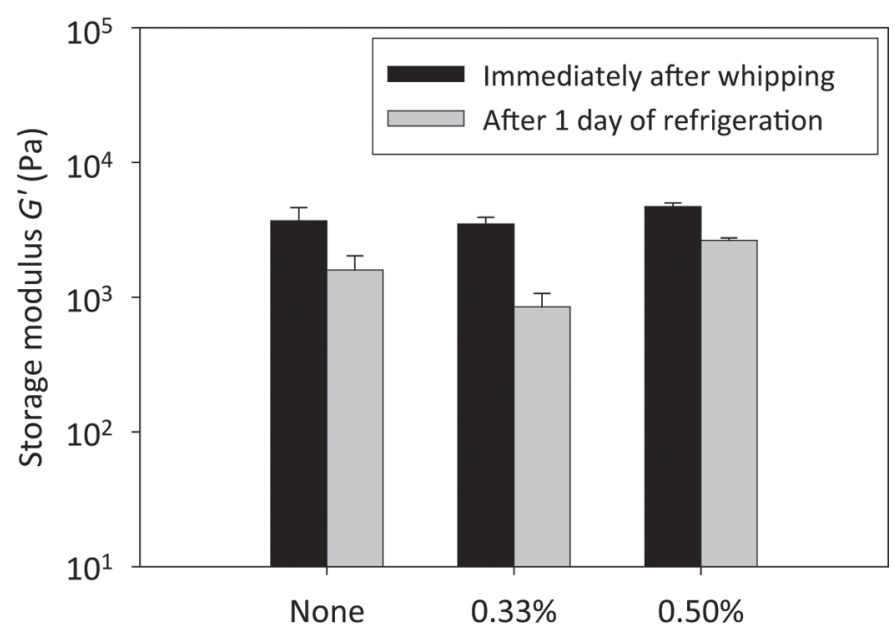

(b)

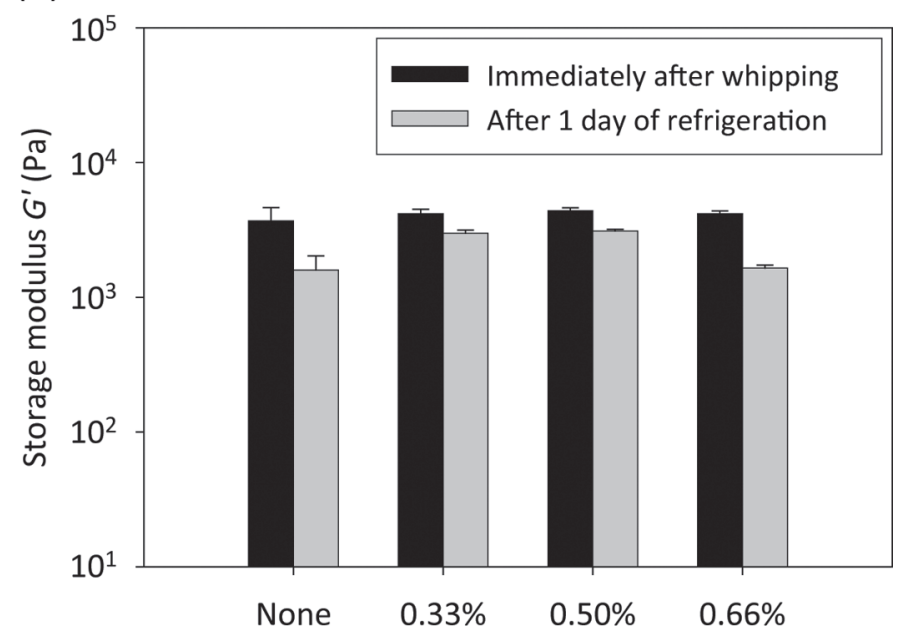

Figure 7. The storage modulus $\left(\mathrm{G}^{\prime}\right)$ value of the dairy cream with (a) sodium caseinate and (b) casein peptide in the continuous phase. The $\mathrm{x}$-axis indicates the percentage of each of the protein components relative to that of the total cream. Data are mean and standard deviation values $(\mathrm{n}=3)$.

shape-retention ability. On the other hand, the addition of sodium caseinate had only a minor effect. Therefore, the effect of casein peptide may be attributable to its specific characteristics rather than simply to its general characteristic as an intact protein. It is known that air bubbles are stabilized by the adsorption of fat globules (Dickinson and Stainsby, 1982; Anderson and Brooker, 1988); thus, some of the fat globules on the surface of the air bubbles are needed to build the structure of the whipped cream. Peptides are known to adsorb onto air bubbles (Kannan et al., 2012), stabilizing their surface. Moreover, the surface area of bubble expresses the firmness of whipped cream (Ihara et al., 2010); thus, (a)

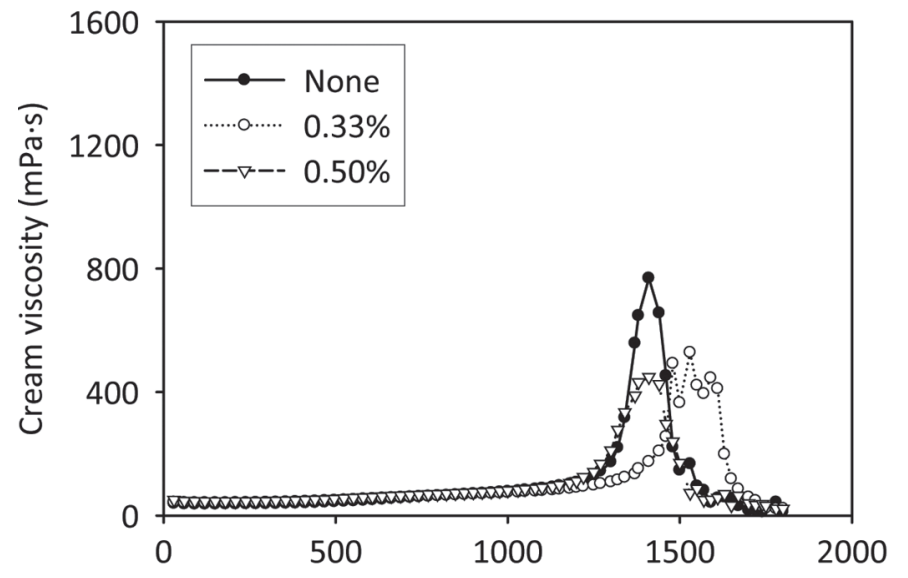

(b)

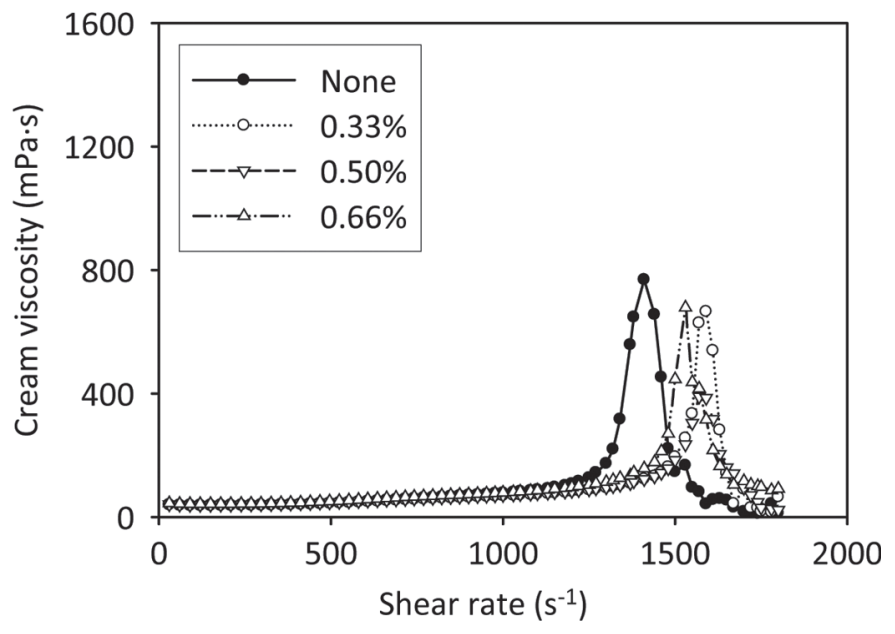

Figure 8. Shear stability of the dairy cream with (a) the emulsifier $(0.06 \%)$ and sodium caseinate at 0.00 (none), 0.33 , and $0.50 \%$, or (b) casein peptide at 0.00 (none), 0.33 , and $0.66 \%$ in the continuous phase. The concentration values refer to percentages of either the sodium caseinate or casein peptide relative to the total cream.

the effect of casein peptide on bubble stabilizing might at least partially cause the improvement of the shape retention ability. This discussion should be validated in the future.

\section{CONCLUSIONS}

We found in this study that the LMWE in the continuous phase of cream stabilized the fat globules and diminished the shape-retention ability of whipped cream. The presence of casein partial hydrolysate (casein peptide) in the continuous phase of cream containing the LMWE improved the shape-retention ability, but left the serum viscosity unchanged. This effect was not 


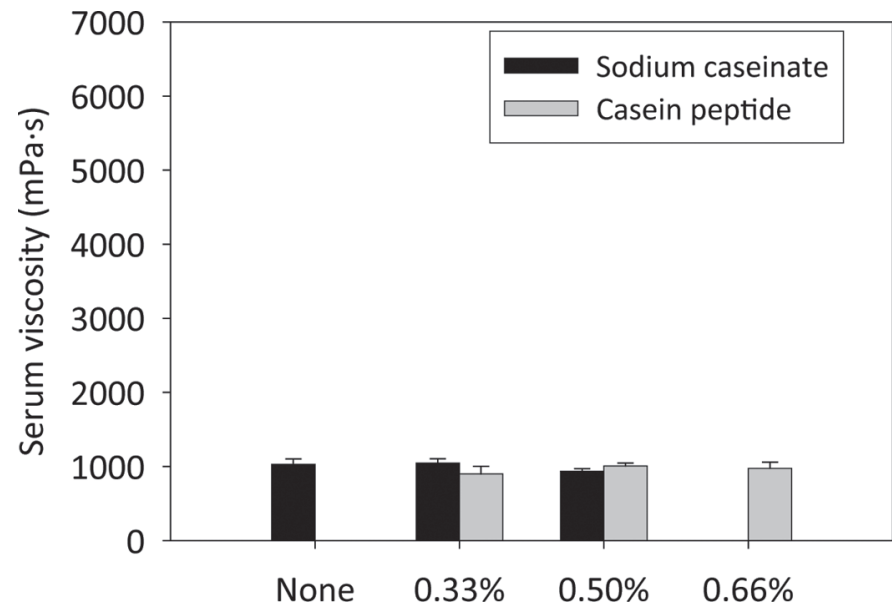

Figure 9. Serum viscosity of the whipped dairy cream with the emulsifier $(0.06 \%)$ and sodium casein at 0.00 (none), 0.33 , and $0.50 \%$, or casein peptide at 0.00 (none), $0.33,0.50$, and $0.66 \%$, in the continuous phase. The $\mathrm{x}$-axis indicates the percentage of either sodium casein or casein peptide relative to the total cream. Data are mean and standard deviation values $(\mathrm{n}=3)$.

observed with sodium caseinate (intact casein) in place of casein peptide; thus, peptides may play at least a partial role in this phenomenon. The findings presented herein demonstrate the ability to improve the whipping properties of cream by using emulsifying components. The appropriate implementation of these findings may result in the development of a high-quality whipping cream.

\section{REFERENCES}

Anderson, M., and B. E. Brooker. 1988. Dairy foams. Pages 221-253 in Advances in Food Emulsion and Foams. E. Dickinson and G. Stainsby, ed. Elsevier, London, UK.

Britten, M., and H. J. Giroux. 1991. Emulsifying properties of whey protein and casein composite blends. J. Dairy Sci. 74:3318-3325. http://dx.doi.org/10.3168/jds.S0022-0302(91)78519-6.

Cornec, M., P. J. Wilde, P. A. Gunning, A. R. Mackie, F. A. Husband, M. L. Parker, and D. C. Clark. 1998. Emulsion stability as affected by competitive adsorption between an oil-soluble emulsifier and milk proteins at the interface. J. Food Sci. 63:39-43. http:// dx.doi.org/10.1111/j.1365-2621.1998.tb15671.x.

Dickinson, E., and G. Stainsby. 1982. Colloids in food processing. Pages 462-498 in Colloids in Food. E. Dickinson and G. Stainsby, ed. Applied Science Publishers, New York, NY.

Fredrick, E., B. Heyman, K. Moens, S. Fischer, T. Verwijlen, P. Moldenaers, P. Van der Meeren, and K. Dewettinck. 2013. Monoacylglycerols in dairy recombined cream: II. The effect on partial coalescence and whipping properties. Food Res. Int. 51:936-945. http://dx.doi.org/10.1016/j.foodres.2013.02.006.

Fredrick, E., P. Walstra, and K. Dewettinck. 2010. Factors governing partial coalescence in oil-in water emulsions. Adv. Colloid Interface Sci. $153: 30-42$.

Goff, H. D. 1997. Instability and partial coalescence of whippable dairy emulsions. J. Dairy Sci. 80:2620-2630. http://dx.doi.org/10.3168/ jds.S0022-0302(97)76219-2. (a)

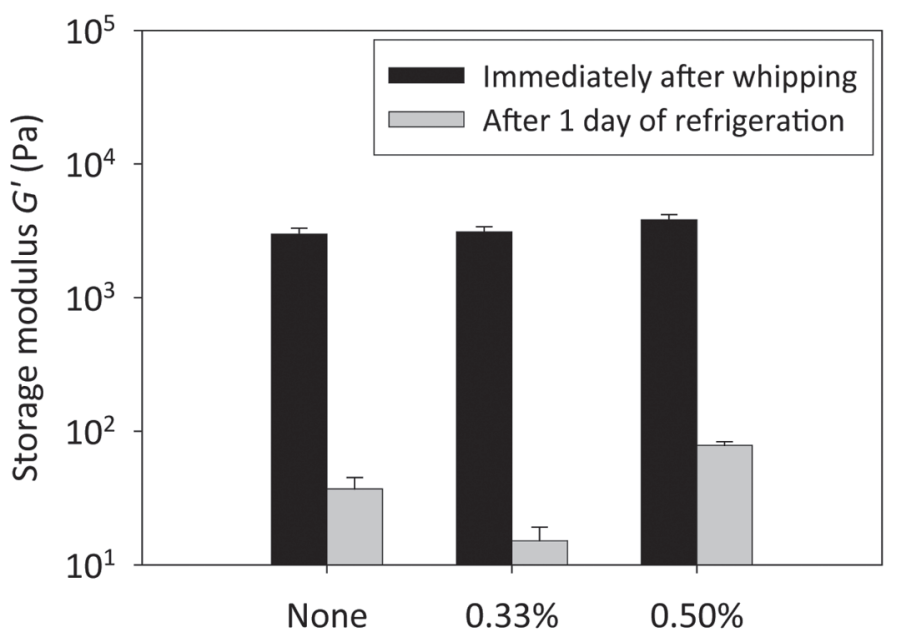

(b)

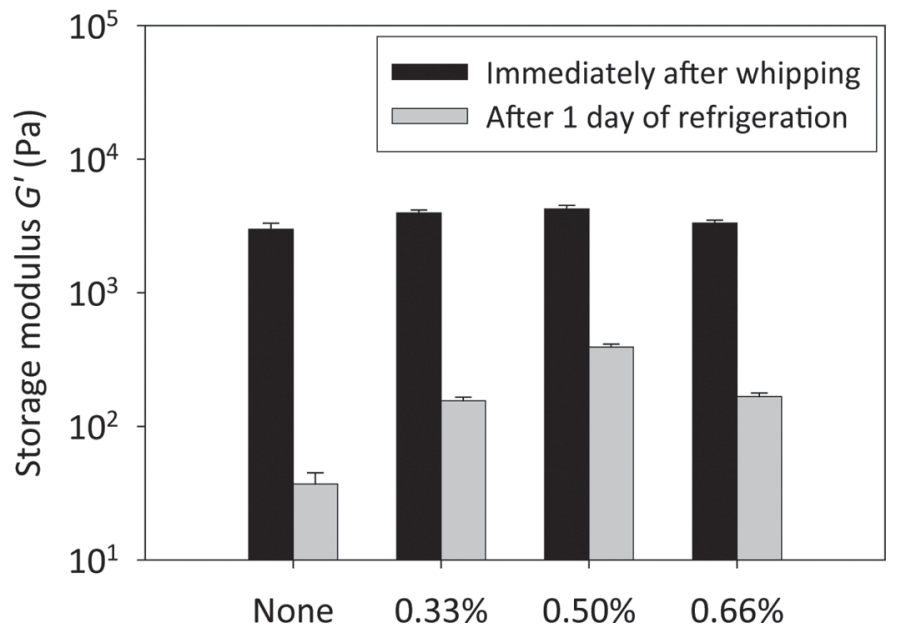

Figure 10. Shape-retention ability of the whipped dairy cream with the emulsifier $(0.06 \%)$ and (a) sodium caseinate at 0.00 (none), 0.33 , and $0.50 \%$, or casein peptide at 0.00 (none), $0.33,0.05$, and $0.66 \%$ in the continuous phase. The concentration values refer to percentages of either sodium caseinate or casein peptide relative to that of the total cream. Data are mean and standard deviation values $(n=3)$.

Hotrum, N. E., M. A. Cohen Stuart, T. Van Vliet, S. F. Avino, and G. A. Van Aken. 2005. Elucidating the relationship between the spreading coefficient, surface-mediated partial coalescence and the whipping time of artificial cream. Colloids Surf. A Physicochem. Eng. Asp. 260:71-78. http://dx.doi.org/10.1016/j.colsurfa.2005.03.004

Ihara, K., K. Habara, Y. Ozaki, K. Nakamura, H. Ochi, H. Saito, H. Asaoka, M. Uozumi, N. Ichihashi, and K. Iwatsuki. 2010. Influence of whipping temperature on the whipping properties and rheological characteristics of whipped cream. J. Dairy Sci. 93:2887-2895. http://dx.doi.org/10.3168/jds.2009-3012.

Ihara, K., C. Kajiya, Y. Shimada, Y. Asano, and S. Kokubo. 2005. Influence of whipping speed on the physical characteristics of whipped cream. J. Jpn. Soc. Food Sci. Technol. 52:553-559. http://dx.doi.org/10.3136/nskkk.52.553.

Kannan, K., N. Hettiarachchy, and M. Marshall. 2012. Proteins and peptides as foaming agents. Pages $151-164$ in Food Proteins and 
Peptides. N. S. Hettirachchy, K. Sato, M. R. Marshall, and A. Kannan, ed. CRC Press, Boca Raton, FL.

Matsumura, Y., and K. Matsumiya. 2012. Proteins-peptides as emulsifying agents. Pages 125-149 in Food Proteins and Peptides. N. S. Hettirachchy, K. Sato, M. R. Marshall, and A. Kannan, ed. CRC Press, Boca Raton, FL.

Noda, M., and Y. Shiinoki. 1986. Microstructure and rheological behavior of whipping cream. J. Texture Stud. 17:189-204. http:// dx.doi.org/10.1111/j.1745-4603.1986.tb00404.x.

Okuyama, S., M. Uozumi, and M. Tomita. 1995. Studies on manufacturing process of whipping cream part I. Application of a cone and plate viscometer to evaluation of physical properties of whipping cream. J. Jpn. Soc. Food Sci. Technol. 42:969-976. http://dx.doi. org/10.3136/nskkk.42.969.

Panyam, D., and A. Kilara. 2004. Emulsifying peptides from the tryptic hydrolysis casein. J. Food Sci. 69: FCT154-FCT163. http:// dx.doi.org/10.1111/j.1365-2621.2004.tb13351.x.

Van Aken, G. A. 2001. Aeration of emulsions by whipping. Colloids Surf. A Physicochem. Eng. Asp. 190: 333-354. http://dx.doi. org/10.1016/S0927-7757(01)00709-9.
Walstra, P., J. T. M. Wouters, and T. J. Geurts. 2006. Cream products. Pages 447-466 in Dairy Science and Technology, 2nd ed. (Food Science and Technology series). P. Walstra, J. T. M. Wouters, and T. J. Geurts, ed. Taylor and Francis Group, Boca Raton, FL.

Wilde, P., and D. C. Clark. 1993. The competitive displacement of lactoglobulin by Tween 20 from oil-water and air-water interfaces. J. Colloid Interface Sci. 155:48-54. http://dx.doi.org/10.1006/ jcis.1993.1008.

Wilde, P. J., A. R. Mackie, M. J. Ridout, F. A. Husband, G. K. Moates, and M. M. Robins. 2007. Role of protein-stabilized interfaces on the microstructure and rheology of oil-in-water emulsions. Pages 385-397 in Food Colloids: Self-Assembly and Material Science. E. Dickinson, and M. R. Leser, ed. The Royal Society of Chemistry, Cambridge, UK.

Zhao, Q., W. Kuang, Z. Long, M. Fang, D. Liu, B. Yang, and M. Zhao. 2013. Effect of sorbitan monostearate on the physical characteristics and whipping properties of whipped cream. Food Chem. 141:1834-1840. http://dx.doi.org/10.1016/j.foodchem.2013.04.086. 